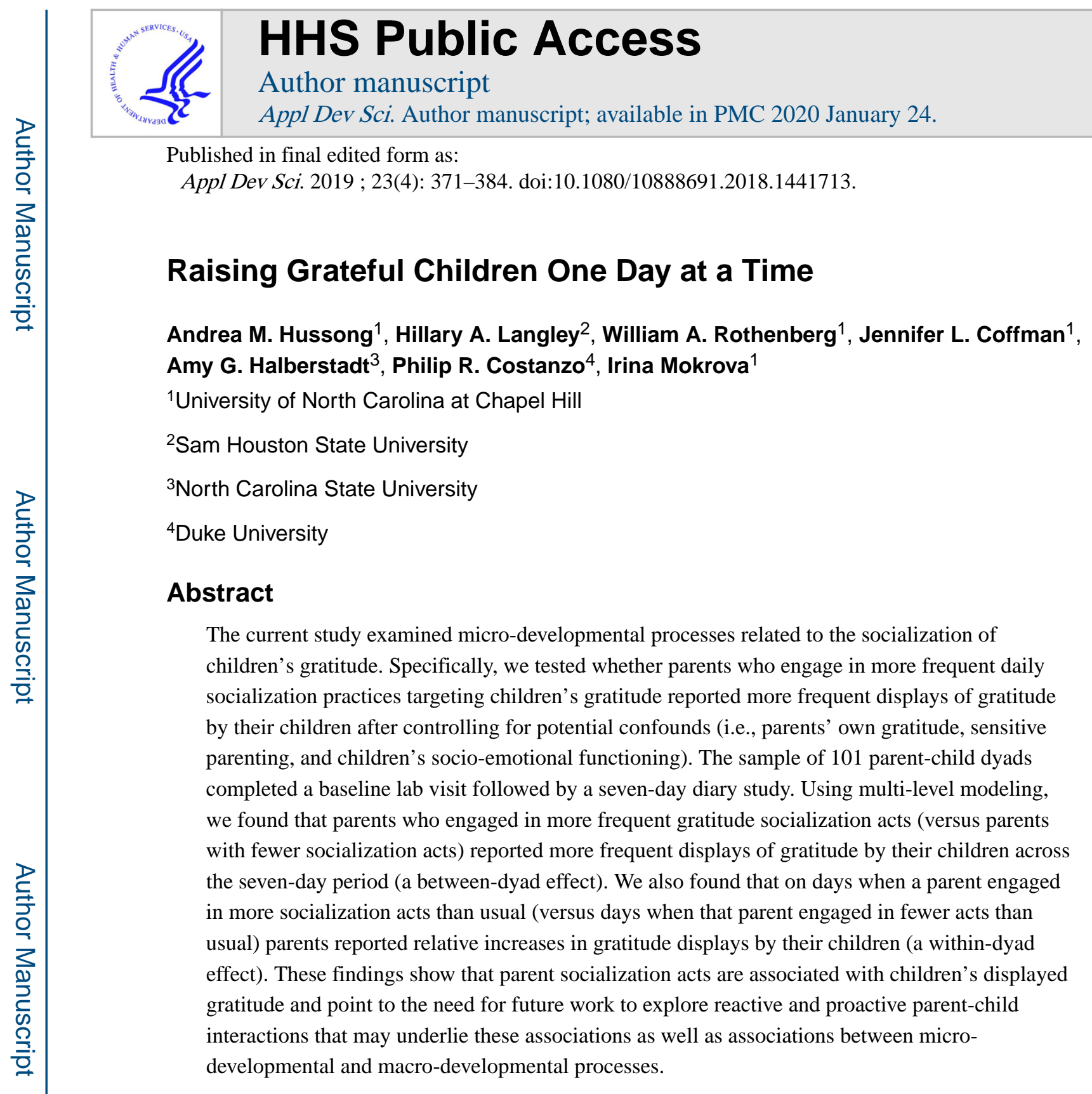

\title{
Keywords
}

gratitude; socialization; positive emotion; parent; child

\begin{abstract}
Technological advances in assessment procedures have re-awakened an old tension in Developmental Science, namely the relative contributions of studies focused on microdevelopmental processes that occur in days, weeks or minutes versus macro-developmental processes that unfold over years (Bronfenbrenner \& Morris, 1998). This tension reflects a fundamental demarcation of the field in identifying "what is development". However, more recent thinking suggests that it is the simultaneous study of micro- and macro-development that may be most likely to lead to high impact developmental science (e.g., Gerstof,
\end{abstract}

Correspondence concerning this article should be addressed to Andrea M. Hussong, Center for Developmental Science, University of North Carolina at Chapel Hill, Chapel Hill, NC, 27599. Phone: 919-962-0333; Fax: 919-966-4520; hussong @ unc.edu. 
Hoppman \& Ram, 2014; Kunnen, Lichtwarck-Aschoff, \& van Geert, 2012; Ram \& Dihel, 2015). Studies of micro-development may describe mechanisms that recur and create enduring processes over time, leading to macro-developmental change. Indeed, many theories have posited such a link (e.g., Snyder, 2002) and diary and experience sampling studies lend support to the existing of these processes (Gottfredson \& Hussong, 2011; Patrick, Maggs \& Lefkowitz, 2015).

We assume that the micro-developmental process of gratitude socialization tested in the current study underlies a macro-developmental process that leads to trajectories of increasing gratitude in children over the years. Specifically, we post that microdevelopmental socialization processes that include cumulative exposure of children to parental modeling of gratitude-related behaviors, positive reinforcement for children's displayed gratitude, repeated support for gratitude behavior in selected niches, and conversations about gratitude moments in part shape children's own gratitude experience. These mechanisms, however, each unfold over moments. We believe, as have other socialization theorists (Bronfenbrenner \& Morris, 1998; 2006), that it is the quantity and quality of such socialization moments that shape the trajectories of child development, including, in our case, children's awareness, thoughts, feelings and behaviors that constitute gratitude. By first testing whether such socialization moments do indeed relate to increased gratitude within a parent-child dyad at the micro-level, we examine a fundamental assumption of this developmental socialization model. Given that the socialization of gratitude is a nascent field, we believe this is a reasonable place to start.

\section{Children's Gratitude}

Social psychologists spearheading research that has shaped our understanding of gratitude in adults differentially adopt the view of gratitude as a life orientation (Wood, Froh, \& Geraghty, 2010), a character, virtue or personality trait (Freitas, Pieta, \& Tudge, 2011; Froh, Sefick, \& Emmons, 2008), and a mood or emotional state (Froh et al., 2008; McCullough, Emmons \& Tsang, 2002; Wood et al., 2010). As an emotion, gratitude has been defined as "a sense of thankfulness and joy in response to receiving a gift, whether the gift be a tangible benefit from a specific other or a moment of peaceful bliss evoked by natural beauty" (Emmons, 2004, p. 554). Differentiating gratitude from other positive emotions, Emmons and McCullough (2003) note that gratitude occurs when recipients view gifts as a positive benefit received not through their own efforts but as freely and purposefully given by a benefactor. Research based on this tradition shows that adults who endorse gratitude traits report greater life satisfaction, better health outcomes, and lower psychopathology (Wood et al., 2010) as well as more optimal social functioning (Emmons \& McCullough, 2004), positive affect, and happiness (Emmons \& McCullough, 2003; Froh, Kashdan, Ozimkowski, $\&$ Miller, 2009). Studies that extend this line of research on gratitude from adults to adolescents suggest that gratitude may hold similar benefits for youth, with results showing that gratitude in youth is associated with positive affect, optimism, satisfaction with social relationships and lower levels of symptomatology (Froh et al., 2011; Froh, Yurkewicz, \& Kashdan, 2009; Park \& Peterson, 2006). 
However, some researchers question how early gratitude may be experienced (Layous \& Lyubomirsky, 2014). Moreover, adapting measures of gratitude from studies of adults assumes both that the underlying construct of gratitude is constant across development and that the indicators of gratitude are similar as well. Although this may be true for some constructs (those exemplifying homotypic continuity), for others the expression of an underlying construct changes across development even if the underlying construct itself remains constant (heterotypic continuity; Cairns, Elder, \& Costello, 2001). It is not clear whether gratitude functions as a homotypic or heterotypic construct. Perhaps more importantly, definitions of gratitude derived from studies of adults focus on what gratitude may look like at the end of a developmental process. By adopting definitions of gratitude from the adult literature to study children, we may miss important components of gratitude that are fundamental to understanding how gratitude emerges over time.

In contrast, two lines of research use a developmentally-informed model to define gratitude with the goal of identifying and tracking the developmental precursors to gratitude in childhood as it first emerges. The earliest of these focused on thanking behaviors specifically. For example, Gleason and Weintraub (1976) made audio-recordings of children on their Halloween rounds and found that 6-year-olds thanked adults for giving them candy noticeably less often (21\%) than did 10-year olds (83\%) and 11- to 16-year-olds (88\%). Although providing a relatively concrete measure of children's gratitude, these studies offer a narrow definition of gratitude that may equally reflect social conformity. More recent work incorporates children's perspective-taking skills into the study of gratitude using vignettes. For example, Nelson and colleagues (Nelson et al., 2013) found that by age 5, most children associated receiving a benefit with positive feelings, sometimes connecting those positive feelings specifically to the benefactor and his or her actions. They also reported that understanding of gratitude at age 5 was predicted by knowledge about emotions more generally at age 3 and understanding of others' mental states at ages 3 and 4 (Nelson et al., 2013). These studies indicate that both behavioral and cognitive components of gratitude are emergent over childhood and are related to gratitude displays.

In the current study, we study children's gratitude with a definition informed by both developmental work on gratitude precursors and studies of gratitude in adults with the goal of capturing the components of gratitude that emerge over development and are targets of parents' socialization efforts. Our definition takes into account the relevant social psychology literature, studies on socio-emotional development, and results of thematic analysis of gratitude-related focus groups conducted with parents and children (Halberstadt et al., 2016). Based on these sources, we define gratitude as a cognitively-mediated, socioemotional process that results in a sense of appreciation, happiness, or joy due to the appraisal of having received something, not due to personal effort but to a benefactor's free and unrestricted intentions to give, that may result in acts of appreciation (see Figure 1). To experience gratitude, we posit that children must be aware that something has been received and then make meaning of the gift by connecting that awareness with positive affect and attributing that positive affect to the benefactors' intentional and freely chosen behavior. We expect that the positive affect that children feel about what they receive along with the attributions that they make about their benefactors together engender the experience of gratitude by connecting the positive experience of gratitude with the actions of another 
person. The result of this process is often behaviors that express appreciation. This definition of gratitude, thus, does not distinguish between experience and expression of gratitude, but encompasses both such that behavior is part of but not required for gratitude.

Reflecting our core interest in studying the development of gratitude, we view this process as emergent, appearing as antecedent immature (not fully formed) experiences in children that become more complex and fully formed with maturation. As a result, we conceptualize the development of gratitude as the integration of key components of this process over time and recognize that although adults may experience all components in this process, children's gratitude may initially involve only some (e.g., recognizing and being joyful about something received but without attributions about the givers' intentions). For this reason, we assessed gratitude as potentially involving each of these components and not only as behaviors that express appreciation. However, because we focus on parents' reports of children's gratitude, in the current study we are most centrally concerned with children's gratitude displays that may reflect not only appreciative behavior but also behaviors that indicate that children are engaging in any component of the gratitude process (see Appendix A).

\section{Daily Acts of Parent Socialization}

Systems theory approaches to understanding family processes posit that the interactions that occur within parent-child dyads are often transactional in nature, encompassing proactive parenting effects on children and reactive parenting behaviors in response to children's actions (Bornstein, 2015). Within this framework, what is traditionally understood as the effects of parenting on child outcomes may in fact reflect a more dynamic, relational microprocess in which parents not only shape but are shaped by their interactions with their children. Children, on the other hand, are not simply passive recipients of parent socialization but may play an active role in shaping the type of parent socialization they receive. Evidence of the bidirectional effects of parent and child behavior on one another are abundant in the literature and elucidate relevant mechanisms that underlie salient child outcomes such as the interacting roles of maternal sensitivity and child temperament in predicting children's attachment status (Rothbart, 2011) and the reciprocal associations among the use of corporal punishment by parents and the presence of behavioral problems in children (Lansford et al., 2011). Although often applied to understanding negative child outcomes, dynamic parent-child mechanisms are also a useful framework for understanding positive child outcomes. Unfortunately, parenting processes related to children's positive developmental outcomes have lagged behind those of negative outcomes (though see Bornstein, 2015 for a rich discussion of various parent-child transactional influences across a variety of outcomes) and this family systems framework has yet to be applied to the study of children's gratitude.

Although little research has focused on the types of parenting behaviors that may cultivate or occur in response to children's displayed gratitude, the literature on parent emotion socialization has examined a broad set of behaviors through which parents shape the emotional development of their children (Eisenberg, Cumberland, \& Spinrad, 1998a). Although much of the research on parent emotion socialization focuses on how parents 
respond to children's distress (a negative outcome) and on proactive (rather than reactive) parenting behaviors, studies of parent emotion socialization have examined a variety of mechanisms that may impact both positive and negative child emotional outcomes such as modeling, teaching, and reinforcing desirable emotional responses, and creating experiences that foster effective emotional regulation in children (Eisenberg, Spinrad, \& Cumberland, 1998b; Morris, Silk, Steinberg, Myers, \& Robinson, 2007). We contribute to a broader understanding of parent emotion socialization by examining whether children's displayed gratitude is associated with parents' engagement in these socialization acts with the goal of fostering children's gratitude. By doing so, we provide an opportunity for understanding the cross-over in socialization strategies associated with the development of negative and positive emotions and investigate an understudied emotional experience that is highly correlated with a number of dimensions of positive functioning in adults. We also extend this literature by differentiating between the broad patterns of how parenting and children's displayed gratitude are related and the day-to-day associations between parenting and children's displayed gratitude and by considering how children's displayed gratitude predicts parents' reactive acts of socialization.

We examined whether children's displayed gratitude was associated with parents' daily acts of emotion socialization directed toward gratitude by examining a variety of socialization acts. First, we considered multiple ways in which parents may socialize their children's emotion including modeling, their reactions to children's emotional expressions, their discussions with children about emotion, and parents' selection of experiences for children with the intent of fostering positive emotional development (Eisenberg et al., 1998a; Eisenberg, Spinrad, \& Cumberland, 1998b). Although we expect these socialization acts to provide a coherent approach to parenting that predicts children's displayed gratitude, existing literature is thin to lacking.

According to social learning theory (Bandura, 1977), parent modeling is a potentially salient mechanism through which children learn about the benefits and consequences of a behavior, and previous studies suggest that parents' gratitude is associated with gratitude displayed by their children (Hoy, Suldo, \& Mendez, 2013; Rothenberg et al., 2017). These studies also show that more supportive responses (e.g., expressive encouragement, emotion-focused responses, and problem-focused responses) increase social competence and that more restrictive responses (e.g., distress reactions, punitive responses, minimization responses) increase risk for symptomatology (Eisenberg, Spinrad, \& Smith, 2004; Eisenberg, Fabes, \& Murphy, 1996). However, no work has extended this mechanism to positive emotions such as gratitude.

Although not yet a focus of study, parent-child discussions may shape children's experience of gratitude by raising awareness about what children have received, helping children recognize their positive affect in reaction to receiving something, assisting children in making attributions regarding their benefactors' actions, and supporting children in finding ways to express appreciation. Similar to processes identified in the autobiographical memory literature (e.g., Fivush, Haden, \& Reese, 2006; Fivush \& Wang, 2005), we anticipate that these conversations are a mechanism whereby children can internalize parental values and attitudes consistent with gratitude. 
Finally, parents may socialize emotion such as gratitude through the physical settings or niches in which they place their children (Eisenberg et al., 1998b; Fredrickson, 1998; Rothenberg et al., 2017). These contexts provide opportunities for children to have experiences that reflect parents' values concerning what is important for children's socioemotional development. Although a central feature in parental socialization, niche-selection has been infrequently studied in the developmental literature, except cross-culturally (see for example, Halberstadt \& Lozada, 2011; Super \& Harkness, 1986). However, in a previous study using the same sample as in the current study, we found that children's displayed gratitude was associated with parents more strongly endorsing the goal of selecting children's activities to promote gratitude as well as with parents actively choosing children's activities in accordance with those goals (Rothenberg et al., 2017).

To assess whether these acts of socialization occur at the micro-level within the daily lives of parents to foster children's displayed gratitude, we assessed whether on each of seven days parents displayed gratitude in front of their children (modeling), responded positively to children's displays of gratitude (parent reactions to children's emotional expressions), talked with children about experiences of receiving something from others (parent-child discussions), and selected activities for children designed to foster gratitude (niche selection).

\section{The Current Study}

We examined the relation between parents' daily acts of socialization and children's displayed gratitude in a sample of 101 parent-child dyads as part of a larger study on the development of gratitude in children and various forms of parent socialization. In examining the link between daily acts of socialization and parents' reports of children's daily displayed gratitude, we tested six hypotheses. First, we predicted that parents who engage in daily acts of socialization will more frequently report greater displayed gratitude in their children (a between-dyad prediction; hypothesis 1). Second, we predicted that any given child will display relative increases in gratitude on days when his or her parent engages in relatively more socialization acts (a within-dyad prediction; hypothesis 2). In addition, we expected specificity in the parent socialization of gratitude such that these between- and within-dyad associations would hold above and beyond parents' own gratitude and overall sensitive parenting style (hypothesis 3 ) as well as other forms of socio-emotional functioning in children (hypothesis 4). We also explored whether these associations held for measures of children's gratitude that did not include expressions of appreciation that may overlap with manners (hypothesis 5). Finally, to attempt to differentiate reactive and proactive parent socialization acts as related to children's displayed gratitude, we predicted that parents' socialization acts on one day will predict children's displayed gratitude the next day and that children's displayed gratitude will predict parents' next day socialization acts (hypothesis 6).

\section{Method}

\section{Participants}

Participants included 101 parent-child dyads recruited through mass emails to faculty, staff, and students at an affiliated university, flyers distributed through public and independent 
schools in first to third grade classrooms, and community postings. Study inclusion criteria were English proficiency and having a child aged 6-9. We purposively did not seek to create a highly diverse sample and given the geographic region from which we recruited, the sample was highly homogenous and rather privileged. We chose this recruitment approach because these parents may struggle with cultivating gratitude in children for whom "having things" may be taken for granted. This may be a unique sociocultural context for the development and socialization of children's displayed gratitude. Given that children's gratitude and related socialization experiences may vary over sociocultural contexts, we choose to control this factor by limiting the sociocultural characteristics of the sample because we were not able to study sociocultural differences in the current project (though see Tudge, Freitas, \& O'Brien, 2015 for work on culture and children's gratitude).

Child mean age was 7.4 years ( $S D=1.03$ years; range 6-9); $52 \%$ were female. Parent mean age was 41 years ( $S D=5.2$ years; range $29-54) ; 85 \%$ were mothers, and they self-identified as $81 \%$ European American, 9\% Asian, 5\% African American, 4\% Latino, 1\% American Indian/Alaska Native and 1\% Middle Eastern. Among participating families, $15 \%$ reported an annual income of less than $\$ 50,000$ whereas $63 \%$ reported $\$ 100,000$ or more. Less than $5 \%$ of parents had not completed a college degree and $62 \%$ had completed a masters or doctoral degree. Most families included two parents living together in the home ( $81 \%$ of parents were married and $4 \%$ were in committed, cohabitating relationships); $4 \%$ of families had separated parents and $11 \%$ had divorced parents.

\section{Procedure}

Parent-child dyads completed a lab-based assessment followed by a seven-day online parental diary and one-month follow-up parental survey. At baseline, we obtained parent consent and child assent, administered three observational tasks to parent-child dyads, and asked parents to complete a computerized survey while children completed an intervieweradministered battery in a separate room. Baseline visits lasted about two-hours and families received $\$ 30$. Online daily diaries were administered via Qualtrics beginning the day after the baseline assessment. Diaries were identical each day and took 5-10 minutes to complete. Participants received $\$ 1$ for each completed diary and a $\$ 3$ bonus if they completed all seven diaries. Parents received an email link to complete a 30-minute follow-up survey 28-days after the baseline visit that permitted us to obtain test-retest data for novel measures (not used in the current study). Parents received an additional $\$ 20$ for completing the online survey. Participant retention throughout the study was high; $89 \%$ of parents completed all seven daily diaries and $96 \%$ completed at least five for a total of 682 observations. Data from the baseline and daily diary surveys only were used for current analyses.

\section{Measures}

Covariates.

We measured eleven variables that were used to create a set of covariates in our analyses. Parents reported their gender and age as well as their children's gender and age. We standardized and then averaged five items to index socioeconomic status that included parent report of: (1) approximate family income from the previous year ranging from $0(\$ 9,999$ or 
less) to 13 ( $\$ 200,000$ or more); ( 2 and 3) educational attainment of each parent using a 8point scale that ranged from 1 (some high school) to 8 (completed graduate or professional degree); and, (4 and 5) the MacArthur scale of subjective social status in which parents indicated their own socioeconomic status relative to individuals in the US broadly as well as the socioeconomic status of their family of origin (Adler \& Stewart, 2007). We assessed parents' religious involvement (a potential correlate of parents' socialization of displayed gratitude) with a single item using a scale ranging from 1 (not involved) to 5 (very involved) and parents' social desirability using the Social Desirability Scale-17 (SDS-17; Stöber, 2001). On the SDS-17, parents indicated whether statements were true or false descriptions of themselves. A mean score was calculated from all items to create a scale score, where a higher score indicated greater social desirability $(M=1.54 ; S D=0.20 ; \mathrm{a}=0.71)$.

\section{Daily Diaries.}

The current analyses include three measures drawn from parent reports in the daily diaries: amount of time that parents spent with the child, children's displayed gratitude, and parents' daily acts of socialization to foster children's gratitude. Parents reported on time spent with their children each day, using a 6-point scale ranging from 1 (I did not spend time with my child today) to 6 (7 hours or more), where contact included in person or electronic contact (i.e., phone, texting, email). This variable was used as a control in subsequent analyses to account for differential quality in reporting on child behaviors and opportunity for engaging in acts of parent socialization.

We based the child displayed gratitude measures on our process model of gratitude (see Figure 1) and previously conducted focus groups with parents (Halberstadt et al., 2016). Ten items captured children's displayed gratitude as reported by parents. We designed this measure to reflect awareness of being given a gift (e.g., "my child acknowledged or recognized that they received something when prompted"), making gratitude-related attributions (e.g., "my child recognized the effort or thoughtfulness behind a gift or object they received from others"), experiencing positive affect in response to a gift (e.g., "my child expressed positive feelings when they received something special"), and displaying gratitude behaviors (e.g., "my child used good manners after being given something without being prompted"). The frequency-based response scale included: 0 (Not at all), 1 (once), 2 (2-4 times), 3 (5-10 times), and 4 (11 times or more). Items were averaged within day to create daily indicators of parent-reported child displayed gratitude $(M=0.74, S D=0.48 ; \mathrm{a}=0.78$ 0.89 over days). In tests of construct validity, an average score of parent reports of children's displayed gratitude was significantly correlated with composite scores (based on parent- and child-report) of child empathy ( $r=.34)$, positive affect ( $r=.26)$, prosocial behavior ( $r=.22)$, and social competence $(r=.21)$ as well as with parent-report of child gratitude on an adapted version of the GQ-6 ( $r=.25)$ and child self-report on the adapted GQ-6 ( $r=.24$; Hussong et al., in preparation).

Similarly, 10 items captured parents' daily acts of socialization including attempts to cultivate children's awareness of receiving or having something (e.g., "pointed out to my child that they have received something special"), positive affect in response to receiving (e.g., "asked my child about their feelings when they received something special"), 
gratitude-related attributions (e.g., "asked my child to think about why someone gave them something special or why they received something"), and gratitude behaviors (e.g., "prompted my child to show gratitude in ways beyond good manners"). Additional items assessed parent socialization efforts identified in focus groups, including the parent and child sharing an experience of feeling grateful, the parent pointing out to the child his/her fortune or privilege, the parent modeling gratitude, the parent involving the child in gratitude promoting activities, and the parent's positive reactions to the child's gratitude displays. The response scale for these daily diary items mirrored that for children's displayed gratitude. The ten items were again averaged within day to create daily indicators of parents' daily acts of socialization ( $M=0.72, S D=0.47 ; a=0.79-0.88$ over days; see Appendix A for full scales on both daily diary measures).

\section{Confounding Variables.}

We included variables related to potential confounds of the association between parents' socialization acts and children's gratitude displays. Psychometric properties for these variables are reported in Table 1.

Parents responded to three items from the Algoe Gratitude Questionnaire (AGQ; Algoe \& Stanton, 2012) to assess their own gratitude. Parents reviewed their interactions during the course of the past month and focused on memorable events during which others had performed favors for them, then rated how frequently they had felt each gratitude-related emotion in response to these favors on a scale ranging from 0 (Never) to 7 ( 7 or more times; Cronbach's $a=0.95$ ).

Parent sensitivity was assessed through a lab-based parent-child interaction task. Researchers provided a set of magnet puzzles to each dyad and asked them to replicate designs from a puzzle book. Parents were instructed that this task was for the child, but they could help in any way they normally would in a task like this. The researchers completed two examples with the dyad and then the dyad had 7 minutes to complete puzzles. Parentchild interactions during the task were recorded and later coded to assess levels of parents' sensitivity, support for autonomy, detachment, positive regard for the child, and negative regard for the child (NICHD Early Child Care Research Network, 1999; Wagner, MillsKoonce, Willoughby, Zvara, Cox, \& The Family Life Project Key Investigators, 2015). Trained coders assigned a rating on each of the above constructs using a scale ranging from 1 (not at all characteristic) to 7 (highly characteristic). Approximately $20 \%$ of cases were double-coded and reliabilities for each subscale were high (intraclass correlations $>.80$ ). Differences in double-coded scores were resolved by conferencing to create final scores. Factor analyses guided the creation of an overall sensitive parenting composite score $(a=$. 89) which consisted of all five subscales (an average of the five scores with detachment and negative regard reverse scored). This overall sensitive parenting composite score is used in subsequent analyses.

We also created two factor score regression composite scores to index parent- and childreports of children's socio-emotional functioning respectively. Parent-reported scores were created from four separate measures assessing positive affect, peer relationships, empathy, 
and prosocial behavior. Parents answered five questions assessing child positive affect using items from the Positive and Negative Affect Schedule for Children - Parent Version (PANAS-C-P; Ebesutani, Okamura, Higa-McMillan, \& Chorpita, 2011; M=3.99(.54); $a=0.82$ ). In addition, parents answered six items adapted from the social competence scale of the child-report version of the Harter Peer Competence Scale for Children (Harter, 1982). For each item, parents read two statements that described two different types of children and then indicated which type of child was most similar to their child. Once parents selected the statement that best described their child, they then indicated the extent to which the statement they selected was true for their child (i.e., "Really true of my child" or "Sort of true of my child"). The two statements were scored together to capture the Harter 4-point response scale ranging from 1 to 4 , where four indicates high social competence ( $\mathrm{M}=3.24(0.60), \mathrm{a}=.80)$. Parents also completed the Child Empathy Attitude Questionnaire (CEAQ; Funk, Fox, Chan, \& Curtiss, 2008) by rating how well 15 statements describe the feelings and reactions of their child using a response scale that ranged from 0 (not like them) to 2 (like them; $M=1.46(.35) ; \mathrm{a}=0.87$ ). Finally, parents completed a subscale assessing children's prosocial behavior from the Strengths and Difficulties Questionnaire (SDQ; Goodman, 1997) using a response scale ranging from 1 (Not true), 2 (Somewhat true), to 3 (Certainly true; $\mathrm{M}=2.54(0.34) ; \mathrm{a}=0.63$ ).

Children's socio-emotional functioning scores were based on similar measures that were designed for child self-report, including the Positive and Negative Affect Schedule for Children - Child Version (PANAS-C; Ebesutani et al., 2011; $M=3.66(0.75) ; a=0.67$ ), the peer relationships scale of the child-report version of the Harter Peer Competence Scale for Children (Harter, 1982; $M=2.86(0.71) ; a=0.74)$, and the Child Empathy Attitude Questionnaire (CEAQ; Funk et al., 2008; $\mathrm{M}=1,47(0.35)$; $a=0.81$ ).

\section{Results}

\section{Factor Score Regression Scores for Children's Socio-Emotional Functioning}

We estimated two measurement models to reduce the dimensionality of the set of variables assessing children's socio-emotional functioning based on parent- and child-report separately and extracted factor score regression composites that served as variables in subsequent analyses. First, we extracted scores from a CFA of the three indicators (empathy, positive affect, and social competence) of a single factor of children-reported socioemotional functioning. Although no fit indices are available for this model (because it is just identified), all items loaded significantly on the single factor ( $z=3.12$ to $4.39, p<0.01$ ). Next, we extracted scores from a CFA of four indicators (empathy, positive affect, social competence as reported on the Harter scales, and prosocial behavior as reported on the Strengths and Difficulties Questionnaire) of a single factor of parent-reported child socioemotional functioning. The model fit adequately on most $\left(\chi^{2}(2)=4.73, p=0.09 ; \mathrm{CFI}=0.94\right)$, though not all, indices (RMSEA $=0.12$, TLI=0.81). Modification indices suggested that local dependence between the indicator of social competence and positive affect accounted for poor model fit and when this covariance was added to the model, fit indices were all acceptable to strong $\left(\chi^{2}(1)=1.09, p=0.30\right.$; RMSEA $=0.03$, CFI=1.0, TLI=.99) and all items loaded significantly on the underlying factor ( $z=2.10$ to $4.47, p<0.05$ ). Factor scores 
regression estimates based on final models were used in subsequent analyses for these two constructs.

\section{Preliminary Covariate Analyses}

We conducted a series of multi-level models (following Curran \& Bauer, 2011) to test study hypotheses. Multi-level models (also known as Hierarchical Linear Models; Raudenbush \& Bryk, 2002) permit regression-style analyses of clustered or nested data (e.g., days nested within children as in the current study) while taking into account non-independence of observations (a necessary assumption of ordinary least squares regression to obtain unbiased estimates). In the current study, data were modeled at two levels to capture daily measures (within-dyad or level-1 measures such as parents' daily socialization acts) and person-child dyad measures (between-dyad or level-2 measures such as parent's self-reported trait gratitude) as predictors of daily measures of children's displayed gratitude. Within-dyad predictors of parent socialization were modeled both as fixed- and random-effects. The fixed-effects reflected the average effect of a within-dyad predictor on the outcome (e.g., the average daily association between increased parent socialization behaviors and children's displayed gratitude within person) and random-effects reflected whether the association of the within-dyad predictor and outcome varied over dyads (e.g., the daily association between socialization acts and displayed gratitude varies over parent-child dyads). In these models, within- and between-dyad effects are orthogonal or independent of one another (when coded appropriately, as described in Curran \& Bauer, 2011). Results of most interest to the current study are fixed-effects of both within- and between-dyad predictors. We report results of these fixed-effects in metrics parallel to ordinary least squares regression - as parameter estimates and z-tests with associated $p$-values.

To first ascertain whether there was significant variation in parents' daily reports of children's displayed gratitude, we estimated an unconditional model. This model contained no predictors but provided estimates of the amount of variance in children's displayed gratitude that was due to within-dyad variation versus between-dyad variation. The resulting unconditional model indicated that parents on average reported that their children had less than one act of displayed gratitude on a given day ( $b=0.75, t=20.2, p<.0001)$ and that children differed from one another substantially in the extent of daily displayed gratitude $(\omega=0.12, z=17.0, p<0.0001)$. In addition, an ICC of .50 indicated that $50 \%$ of the variance in children's daily displayed gratitude was due to between-child effects (variability across children) and 50\% was due to within-child effects (variability across days).

Because prior daily diary and ecological momentary analysis studies have found reactance to the protocol (i.e., increases or decreases in behavior with daily reporting, which should then lead to systematic increases or decreases in behavior over the study period; Shiffman, Stone $\&$ Hufford, 2008), we followed standard procedures to test for reactance in the current model. Specifically, we included day of the assessment protocol (day 0-6) as a predictor of daily reports of child's displayed gratitude, with child displayed gratitude serving as the outcome and assessment day serving as a level-1 (daily) predictor centered at day 1. Linear time trends predicting children's displayed gratitude would indicate that participation in the study may have an impact on parents' reports of children's displayed gratitude. Results 
showed no evidence of reactance ( $b=0.00, z=0.08, p=0.93$ ) and thus the linear effect of assessment day was removed from the model.

We next included the amount of daily contact that parents had with their child both as a within-dyad or daily variable (controlling for whether parents saw their children more or less than usual on a given day) and as a between-dyad variable (controlling for whether some parents saw their children across the week more often than did other parents). By controlling for these effects of parents' contact with children, we were able to test whether parent socialization behaviors were associated with children's displayed gratitude above and beyond the amount of contact parents had with their children. This technique statistically controls for the possibility that more time spent with children is simply more opportunity for parents to observe children's displayed gratitude. More specifically, we entered parents' report of time spent with children as a level-1 person-mean deviation score covariate and as a level-2 person-mean centered covariate. (See Curran \& Bauer, 2011 for details on centering covariates to obtain accurate within- and between-dyad effects.) Results showed significant within-dyad effects. Parents reported greater displayed gratitude in their children on days when they had relatively more contact with their children $(b=0.11, z=11.93$, $p<0.001)$.

We then added to this model several potential control variables, predicting parent reports of children's displayed gratitude from child gender, child age, socio-economic status, parent age, parent gender, parent race/ethnicity (i.e., European American versus Person of Color), marital status (i.e., married versus other), parent religious involvement, and parent social desirability. All effects of these covariates on parent reports of children's displayed gratitude were non-significant (all $p<.05$ ). To examine whether the lack of covariate associations was due to model complexity, we re-estimated this model serially, controlling for each covariate one at a time. Results confirmed that all covariates continued to have nonsignificant associations with children's displayed gratitude. Because non-significant covariates do not control for meaningful variance in the model (i.e., indicating that results will not be due to confounding effects of these covariates), we trimmed covariates from further models with the analytical goal of model parsimony. However, we did retain the effect of time spent with children.

\section{Results of Models Testing Hypotheses 1 to 4}

We next tested hypothesis 1 and 2 regarding the within-dyad and between-dyad effects of parents' daily acts of socialization on children's daily displayed gratitude. Following Curran and Bauer (2011), we entered between-dyad (level 2) and within-dyad (level 1, random- and fixed-) effects of parents' acts of socialization as predictors of children's daily displayed gratitude (see Table 1; Model for Hypothesis 1 and 2). After controlling for time spent with children, parents' daily acts of socialization accounted for $39.6 \%$ of the variance in children's displayed gratitude (the total model accounted for $52.7 \%$ of the variance in this outcome). Parents who used more daily acts of socialization described their children as displaying more gratitude overall than did parents who provided fewer acts of socialization to their children (i.e., between-dyad effect of parents' acts of socialization, $b=0.87, t=14.77$, $p<.001)$. Moreover, on days when parents provided more acts of socialization for their 
children than usual, parents reported that their children displayed more gratitude behaviors than usual (i.e., within-dyad effect of parents' acts of socialization, $b=0.62, t=19.51$, $p<0.001$ ). This finding was consistent with both hypotheses 1 and 2 .

To test whether these effects of parents' daily acts of socialization on children's displayed gratitude depend on child age, we added the main effect of child age to this model and interactions between child age and the within-dyad effect of parents' acts of socialization as well as between child age and the between-dyad effect of parents' acts of socialization.

None of these effects of child age was significant.

We next added level-2 covariates to control for effects of parenting sensitivity and parents' own gratitude (see Table 1; Model for Hypothesis 3). Sensitive parenting was not related to children's displayed gratitude and parents' own gratitude showed only a trend-level association $(b=.03, \mathrm{t}=1.75, \mathrm{p}<.10)$. However, within-dyad and between-dyad effects of parent socialization acts were unchanged and continued to show associations with children's daily displays of gratitude, supporting hypothesis 3 that the between- and within-dyad effects of parent socialization of gratitude would hold above and beyond parents' own gratitude and overall sensitive parenting style.

Testing hypothesis 4, we added level-2 covariates to control for effects of children's socioemotional functioning based on parent and child reports (see Table 1; Model for Hypothesis 4). Parent-reports of children's socio-emotional functioning were related to displayed gratitude in children $(b=.07, \mathrm{t}=3.07, \mathrm{p}<.01)$, although child reports were not. Once again, within-dyad and between-dyad effects of parent socialization acts were unchanged and continued to show associations with children's daily displays of gratitude, supporting hypothesis 4 that the between- and within-dyad effects of parent socialization of gratitude would hold above and beyond socio-emotional functioning in children.

\section{Results of Models Testing Hypothesis 5}

To determine whether findings regarding hypotheses 1-4 held when children's gratitude displays did not include behaviors that are also consistent with manners (and therefore may not reflect gratitude), we re-estimated the models reported in Table 2 using the same measure of children's gratitude displays as above but omitting two items assessing manners. Parameter estimates for daily socialization effects were consistent with previous findings.

\section{Results of Models Testing Hypothesis 6}

To examine the directionality that might underlie the positive daily associations between parent socialization acts and their reports of children's displayed gratitude (hypothesis 6), we estimated two sets of lagged models. The first was identical to that reported in Table 1 for Hypothesis 1 and 2 but used next day children's displayed gratitude as the outcome (as opposed to same day). Results showed that the between-dyad effect of parent socialization acts on children's displayed gratitude held $(b=.89, t=15.50, p<.001)$ but the within-day effect of parent socialization acts on children's next day displayed gratitude was non-significant ( $b=.03, t=0.88, p=\mathrm{ns}$ ). In the second model, the outcome variable was parents' socialization acts (next day) and the within- and between-person predictors were children's displayed 
gratitude, testing a reactive parenting effect. Again, results showed that the between-dyad effect of children's displayed gratitude on parents' socialization acts held ( $b=.80, t=15.33$, $p<.001)$ but the within-day effect of children's displayed gratitude on parents' next day socialization acts was non-significant ( $b=.00, t=0.044, p=\mathrm{ns}$ ). These findings suggest that associations between parent socialization acts and children's displayed gratitude are withinday and do not appear to carry forward from one day to the next.

\section{Discussion}

Using a daily diary approach that investigated micro-level gratitude socialization processes, we found robust associations between parents' socialization efforts and children's displays of gratitude. As predicted, parents who provided more daily acts of socialization regarding gratitude also reported more displayed gratitude in their children across the seven-day assessment window. Parent socialization acts were also associated with the up and down variation in day-to-day displayed gratitude in children. More specifically, within dyads, days on which parents used more socialization acts than usual were associated with relative increases in children's displayed gratitude. These findings were consistent across children ages 6-9 and were maintained after controlling for other potential covariates of children's displayed gratitude (e.g., parents' gratitude, sensitive parenting, and children's socioemotional functioning).

The utility of intensively repeated measures designs, such as the diary design used in the current study, is the ability to link traditional approaches to studying between-dyad effects with more recent approaches to studying within-dyad effects. This design allows us to test assumptions about how broad indicators of complex psychological processes are related to behaviors at the level at which they often occur, in this case within a day. Moreover, they allow us to begin to examine the time-scale over which these associations occur (here, within-day versus next-day).

We posited that positive associations between parents' daily acts of socialization and children's displayed gratitude occur because children who receive more gratitude socialization from their parents in turn learn more about gratitude and perform better (i.e., display gratitude more often) in addition to seeing that their parents value gratitude. This proactive parenting interpretation is indeed consistent with our findings. But a reactive parenting interpretation, in which children drive the parent-child interaction, is also consistent with our findings. Between-dyad effects, however, do not distinguish among the individual behaviors that make-up the pattern of dyadic interactions; rather, they focus on associations that distinguish among dyads.

Perhaps closer to testing a dynamic parent-child interaction hypothesis were our tests of within-dyad effects. We tested these within-dyad effects in a series of models in which parenting socialization acts predicted same-day displayed gratitude in children; in these models, socialization acts were entered as predictors of next day displayed gratitude, and children's displayed gratitude as predictors of next day socialization acts. Our findings showed positive within-day associations between parent socialization acts and children's displayed gratitude, but no next day associations among these two variables regardless of 
directionality. However, we believe that the absence of these lagged effects may not be a strong test of proactive and reactive parenting. A day lag is likely both too short for this pattern of child- versus parent- led interactions to emerge (e.g., repeated exposure to proactive parenting socialization efforts may take longer than a day to impact child outcomes) and too long (e.g., reactive parent reactions to child behavior are likely to be more immediate and not delayed for a single day). Identifying optimal lags in intensively repeated measurement designs remains a challenge, which may be complicated by developmental processes in that children are developing their cognitive capacity for reflection and memory of parental messages. For now, our findings suggest that parent-child interactions involving the socialization and display of gratitude are unlikely to play out reliably from one day to the next for this particular age group. But the significant within-day association between socialization and displayed gratitude suggests that they may play out over a shorter window.

Whether these within-day associations reflect proactive or reactive parenting is unclear in these findings. Indeed, it may be both. Proactive socialization may increase children's displayed gratitude on any given day and, with increasing exposure, over development. Children's displayed gratitude may draw parents' attention to their goals of socializing gratitude and increase parents' engagement in gratitude socialization efforts, resulting in reactive parenting. These processes may occur in isolation or in conjunction on any given day, but over time create a dynamic feedback loop in which parents and children interactively reinforce gratitude socialization acts and displays. More specifically, we anticipate that reactive, or child-driven, parenting is interlaced with proactive, or caretakerdriven, parenting in a manner that shapes child displayed gratitude and parent gratitude socialization over time. The within-dyad effects may be most evident in studies that use intensive repeated designs that investigate these processes at the micro-level. But the longterm effects of this dance between reactive and proactive may be best examined in long-term longitudinal designs that capture stability in these processes at the macro-level. As we continue to follow this sample longitudinally, we will be able to link development that occurs within day with that that unfolds over years. Future studies that pair intensive repeated and long-term longitudinal designs could determine the long-term effect of parents' daily acts of socialization on children's displayed gratitude.

Importantly, the between-dyad finding that families in which parents use more daily acts of socialization have children whom parents perceive as more grateful was highly robust. Between-dyad effects of daily acts of socialization on children's displayed gratitude were evident above and beyond the effects of parents' gratitude, parental sensitivity, and children's socio-emotional functioning. These findings may suggest that the pattern of parent-child interactions that underlie parenting are established prior to the observation period of this study. However, they accounted only for $50 \%$ of the total variance accounted for by these measures and within-dyad effects accounted for the other half.

We did find that children's displayed gratitude was related to parent reports of children's socio-emotional functioning. Parents may view their children as displaying gratitude more frequently when parents viewed their children as having more social competence. Because other studies demonstrate that indicators of children's socio-emotional functioning are expected predictors of children's displayed gratitude (e.g., Nelson et al., 2013), this finding 
provides initial construct validation of our measure of children's displayed gratitude.

However, this effect was not replicated for children's reports of their own socio-emotional functioning. Although the association between parent reports of children's socio-emotional functioning and daily displayed gratitude may in part reflect reporter bias, it may also reflect important differences in reporter perspectives. For example, parents may be more sensitive to the range of socio-emotional functioning that children display and in turn be better able to capture meaningful differences that relate to children's displayed gratitude. Regardless, the effects of parent reports of children's socio-emotional functioning contributed to predict children's displayed gratitude above and beyond both the amount of contact that parents have with their children each day and the parents' use of daily acts of socialization.

Our study has several strengths. First, our design was a unique approach to measuring parent socialization practices and focused on the repeated daily conversations that parents have with their children. Second, our conceptualization of these daily acts of socialization led to the creation of a brief scale that could feasibly be included in a daily diary assessment. We created these items based on all four of the socialization practices theorized as important in the parent emotion socialization literature, including modeling, teaching via conversation, niche selection, and responding to children's emotions. Our previous work indicates that each of these forms of socialization are associated with parent-reports of children's gratitude, though within- and between-day associations have not been examined (Hussong et al., 2017; Rothenberg et al., 2017). These items also reflected different targets of these socialization practices as posited in our emotional process model of children's displayed gratitude that included awareness of receiving something, positive affect associated with that receipt, attributions regarding the benefactor's intent, and behavioral displays of appreciation. The resulting scale assessed acts of socialization not simply as parental prompts for children to say "thank you," but as a broader set of parenting behaviors that may collectively convey to children the importance of gratitude and what children should do to develop a sense of gratitude. The current study provides support for the predictive validity of this scale and of our theoretically-based scale of children's displayed gratitude.

However, the study also has limitations that suggest important future directions. First, the current sample is relatively homogenous and privileged; future research is needed to evaluate the generalizability of findings to families from other sociocultural contexts. To evaluate the impact of shared method variance, additional measures of children's gratitude are needed that do not rely on parent- or child-report surveys and obviate the effects of reporter bias (i.e., grateful parents simply see their children as more grateful) that are present in the current study. The diary study design demands also required a brief measure of parent socialization that was not designed to parse types of parent socialization. Rather, we leave to future research the question of which socialization practices are most effective, for what child, in what situation, and at what point in time. This would allow for the expansion of gratitude as involving not simply daily displays but transformative experiences. In addition, extension to longitudinal data is needed to better understand the interplay of proactive and reactive parenting in the development of children's displayed gratitude.

In sum, the current study tests parents' attempts to socialize gratitude in their children. We offer both a unique perspective on defining and assessing displayed gratitude in children and 
a novel extension of parent emotion socialization models to conceptualize how parents use daily acts of socialization to foster gratitude in their children. The daily diary design permitted us to gain insights into the ways in which micro-level, day-to-day parenting behaviors are associated with child behavior, both within any given day but also cumulatively over time. In short, increases in parents' daily socialization acts are associated with increases in children's displayed gratitude on that day, indicating that changes in individual behavior among parent-child dyads are linked, and parents who reported more daily socialization acts also reported greater gratitude displays in their children in comparison to other parents. In addition, the current study offers novel measures to assess parents' daily socialization efforts and children's displayed gratitude using a developmentally-informed approach to understanding gratitude in children. We believe that this micro-developmental process may underlie macro-developmental associations between parent socialization and increasing trajectories of children's gratitude over time. Future studies are needed to build on this initial finding to determine the developmentally extended effects of such socialization practices as well as exploring the how, when, and where of parents' effective socialization practices for fostering gratitude in their children.

\section{Acknowledgements:}

This research was supported by the Expanding the Science and Practice of Gratitude Project run by UC Berkeley's Greater Good Science Center in partnership with UC Davis with funding from the John Templeton Foundation and by a postdoctoral fellowship provided by the National Institute of Child Health and Human Development (T32HD07376) through the Center for Developmental Science at the University of North Carolina at Chapel Hill to the second author.

\section{Appendix A}

\section{Select Measures}

\section{PARENT-REPORT OF DAILY GRATITUDE SOCIALIZATION BEHAVIORS}

How often today did you do the following with your child who participated in our study?

$0=$ Not at all

$1=$ Once

$2=2-4$ times

$3=5-10$ times

$4=11$ times or more

Q1. Prompted my child to use good manners (i.e., say please, thank you)

Q2. Pointed out to my child that they have received something special

Q3. Talked to my child about a shared experience and emphasized reasons they may be thankful or grateful

Q4. Expressed my own thanks or gratitude in front of my child 
Q5. Asked my child about their feelings when they received something special

Q6. Pointed out that my child has more belongings or privileges than others

Q7. Asked my child to think about why someone gave them something special or why they received something

Q8. Prompted my child to show gratitude in ways beyond good manners

Q9. Praised my child for appropriately expressing gratitude

Q10. Engaged in an activity or went to a place to teach my child about gratitude

PARENT-REPORT OF CHILD'S DAILY GRATITUDE-Please indicate how often you saw the following in your child today.

$0=$ Not at all

$1=$ Once

$2=2-4$ times

$3=5-10$ times

$4=11$ times or more

Q1. My child used good manners when prompted after being given something (i.e., say please, thank you)

Q2. My child used good manners after being given something WITHOUT being prompted (i.e., say please, thank you)

Q3. My child acknowledged or recognized that they received something when prompted

Q4. My child acknowledged or recognized that they had received something on their own WITHOUT my prompting

Q5. My child recognized the effort or thoughtfulness behind a gift or object they received from others

Q6. My child shared an experience in which they were thankful for something

Q7. My child expressed their positive feelings when they received something special

Q8. My child pointed out how fortunate they are to have more than others

Q9. My child talked about why someone gave them something special or why they received something unexpected

Q10. My child expressed gratitude toward others through ways that went beyond good manners

Appl Dev Sci. Author manuscript; available in PMC 2020 January 24. 


\section{References}

Adler N, \& Stewart J (2007). The MacArthur scale of subjective social status. MacArthur Research Network on SES \& Health. Retrieved from http://www.macses.ucsf.edu/Research/Psychosocial/ subjective.php.

Algoe SB, \& Stanton AL (2012). Gratitude when it is needed most: Social functions of gratitude in women with metastatic breast cancer. Emotion, 12, 163-168. doi:10.1037/a0024024 [PubMed: 21707160]

Bandura A (1977). Social learning theory. Oxford, England: Prentice-Hall.

Bornstein M (2015). Children's parents. In Lerner R, Bornstein M, and Leventhal T (Eds.), Handbook of child psychology and developmental science, volumek 4: Ecological settings and processes (pp. 55-222). Hoboken, NJ, US: John Wiley.

Bronfenbrenner U, \& Morris PA (1998). The ecology of developmental processes In Damon W \& Lerner RM (Eds.), Handbook of child psychology: Theoretical models of human development (pp. 993-1028). Hoboken, NJ, US: John Wiley.

Bronfenbrenner U, \& Morris PA (2006). The bioecological model of human development In Lerner RM, Damon W, Lerner RM, Damon W (Eds.), Handbook of child psychology: Theoretical models of human development, Vol. 1, 6th ed. (pp. 793-828). Hoboken, NJ, US: John Wiley \& Sons Inc.

Cairns RB, Elder GH, \& Costello EJ (2001). Developmental science. Cambridge University Press.

Curran PJ, \& Bauer DJ (2011). The disaggregation of within-dyad and between-dyad effects in longitudinal models of change. Annual Review of Psychology, 62, 583-619. doi:10.1146/ annurev.psych.093008.100356

Ebesutani C, Okamura K, Higa-McMillan C, \& Chorpita BF (2011). A psychometric analysis of the Positive and Negative Affect Schedule for Children-Parent Version in a school sample. Psychological Assessment, 23, 406-416. doi:10.1037/a0022057 [PubMed: 21381834]

Eisenberg N, Cumberland A, \& Spinrad TL (1998a). Parental socialization of emotion. Psychological Inquiry, 9, 241-273. doi:10.1207/s15327965pli0904_1 [PubMed: 16865170]

Eisenberg N, Fabes RA, \& Murphy BC (1996). Parents' reactions to children's negative emotions; Relations to children's social competence and comforting behavior. Child Development, 67, 22272247. [PubMed: 9022240]

Eisenberg N, Spinrad TL, \& Cumberland A (1998b). The socialization of emotion: Reply to commentaries. Psychological Inquiry, 9, 317-333. doi:10.1207/s15327965pli0904_17

Eisenberg N, Spinrad TL, \& Smith CL (2004). Emotion-related regulation: Its conceptualization, relations to social functioning, and socialization In Philippot P, Feldman RS (Eds.), The regulation of emotion (pp. 277-306). Mahwah, NJ, US: Lawrence Erlbaum Associates Publishers.

Emmons RA (2004). The psychology of gratitude: An introduction In Emmons RA, McCullough ME (Eds.), The psychology of gratitude (pp. 3-16). New York, NY, US: Oxford University Press.

Emmons RA, \& McCullough ME (2003). Counting blessings versus burdens: An experimental investigation of gratitude and subjective well-being in daily life. Journal of Personality and Social Psychology, 84, 377-389. doi:10.1037/0022-3514.84.2.377 [PubMed: 12585811]

Emmons RA, \& McCullough ME (2004). The psychology of gratitude. New York, NY, US: Oxford University Press.

Fivush R, Haden CA, \& Reese E (2006). Elaborating on elaborations: Maternal reminiscing style and children's socioemotional outcome. Child Development, 77, 1568-1588. doi:10.1111/j. 1467-8624.2006.00960.x [PubMed: 17107447]

Fivush R, \& Wang Q (2005). Emotion talk in mother-child conversations of the shared past: The effects of culture, gender, and event valence. Journal of Cognition and Development, 6, 489-506. doi:10.1207/s15327647jcd0604_3

Fredrickson BL (1998). Cultivated emotions: Parental socialization of positive emotions and selfconscious emotions. Psychological Inquiry, 9, 279-281. doi:10.1207/s15327965pli0904_4

Freitas LB, Pieta MM, \& Tudge JH (2011). Beyond politeness: The expression of gratitude in children and adolescents. Psicologia: Reflexão E Crítica, 24, 757-764. doi:10.1590/ S0102-79722011000400016 
Froh JJ, Fan J, Emmons RA, Bono G, Huebner ES, \& Watkins P (2011). Measuring gratitude in youth: Assessing the psychometric properties of adult gratitude scales in children and adolescents. Psychological Assessment, 23, 311-324. doi:10.1037/a0021590 [PubMed: 21443367]

Froh JJ, Kashdan TB, Ozimkowski KM, \& Miller N (2009). Who benefits the most from a gratitude intervention in children and adolescents? Examining positive affect as a moderator. The Journal of Positive Psychology, 4, 408-422. doi:10.1080/17439760902992464

Froh JJ, Sefick WJ, \& Emmons RA (2008). Counting blessings in early adolescents: An experimental study of gratitude and subjective well-being. Journal of School Psychology, 46, 213-233. doi: 10.1016/j.jsp.2007.03.005 [PubMed: 19083358]

Froh JJ, Yurkewicz C, \& Kashdan TB (2009). Gratitude and subjective well-being in early adolescence: Examining gender differences. Journal of Adolescence, 32, 633-650. doi:10.1016/ j.adolescence.2008.06.006 [PubMed: 18760465]

Funk J, Fox C, Chan M, \& Curtiss K (2008). The development of the Children's Empathic Attitudes Questionnaire using classical and Rasch analyses. Journal of Applied Developmental Psychology, 29, 187-196. doi:10.1016/j.appdev.2008.02.005

Gerstorf D, Hoppmann CA, \& Ram N (2014). The promise and challenges of integrating multiple time-scales in adult developmental inquiry. Research in Human Development, 11, 75-90.

Gleason JB, \& Weintraub S (1976). The acquisition of routines in child language. Language in Society, 5, 129-136. doi:10.1017/S0047404500006977

Goodman R (1997). The Strengths and Difficulties Questionnaire: A research note. Child Psychology \& Psychiatry \& Allied Disciplines, 38, 581-586. doi:10.1111/j.1469-7610.1997.tb01545.x

Gottfredson NC, \& Hussong AM (2011). Parental involvement protects against self-medication behaviors during the high school transition. Addictive Behavior, 36, 1246-1252. doi: 10.1016/ j.addbeh.2011.07.035

Halberstadt AG, Langley HA, Hussong AM, Coffman JL, Rothenberg WA, Mokrova I, \& Costanzo PR. (2016). Parents' understanding of gratitude in young children: A thematic analysis. Early Childhood Research Quarterly, 26, 439-451. doi:10.1016/j.ecresq.2016.01.014

Halberstadt AG, \& Lozada FT (2011). Emotion development in infancy through the lens of culture. Emotion Review, 3, 158-168. doi:10.1177/1754073910387946

Harter S (1982). The Perceived Competence Scale for Children. Child Development, 53, 87-97. doi: $10.2307 / 1129640$

Hoy BD, Suldo SM, \& Mendez LR (2013). Links between parents' and children's levels of gratitude, life satisfaction, and hope. Journal of Happiness Studies, 14, 1343-1361. doi:10.1007/ s10902-012-9386-7

Hussong AM, Langley HA, Coffman JL, Halberstadt AG, \& Costanzo PR (2017). Parent socialization of children's gratitude In Tudge J and Freitas L (Eds.), Developing Gratitude, (pp. 199-219). Cambridge University Press.

Hussong AM, Langley HA, Taylor TE, Coffman JL, Halberstadt AG, \& Costanzo PR (2017). Measuring gratitude as a complex emotional process in children. Manuscript in preparation.

Kunnen S, Lichtwarch-Aschoff A, \& van Geert P (2012). The search for relations between micro and macro development In Kunnen S (Ed.), A dynamic systems approach to adolescent development (pp. 153-162). New York, NY, US: Psychology Press.

Lansford JE, Malone P, Dodge K, Chang L, Chaudry N, Tarnpaya S, Oburu P, \& Deater-Deckard K (2010). Children's perceptions of maternal hostility as a mediator of the link between discipline and children's adjustment in four countries. International Journal of Behavioral Development, 34, 452-461. [PubMed: 20823943]

Layous K, \& Lyubomirsky S (2014). Benefits, mechanisms, and new directions for teaching gratitude to children. School Psychology Review, 43, 153-159.

McCullough ME, Emmons RA, \& Tsang J (2002). The grateful disposition: A conceptual and empirical topography. Journal of Personality and Social Psychology, 82, 112-127. doi: 10.1037/0022-3514.82.1.112 [PubMed: 11811629]

Morris AS, Silk JS, Steinberg L, Myers SS, \& Robinson LR (2007). The role of the family context in the development of emotion regulation. Social Development, 16, 361-388. doi:10.1111/j. 1467-9507.2007.00389.x [PubMed: 19756175] 
Muthén LK, \& Muthén BO (2012). Statistical analysis with latent variables. User's Guide, Version, 7.

Nelson JA, Freitas LL, O’Brien M, Calkins SD, Leerkes EM, \& Marcovitch S (2013). Preschool-aged children's understanding of gratitude: Relations with emotion and mental state knowledge. British Journal of Developmental Psychology, 31, 42-56. doi:10.1111/j.2044-835X.2012.02077.x [PubMed: 23331105]

NICHD Early Child Care Research Network (1999). Child care and mother-child interaction in the first three years of life (1999). Developmental Psychology, 35, 1399-1413. doi: 10.1037/0012-1649.35.6.1399 [PubMed: 10563730]

Park N, \& Peterson C (2006). Character strengths and happiness among young children: Content analysis of parental descriptions. Journal of Happiness Studies, 7, 323-341. doi:10.1007/ s10902-005-3648-6

Patrick ME, Maggs JL, \& Lefkowitz ES (2015). Daily associations between drinking and sex among college students: A longitudinal measurement burst design. Journal of Research on Adolescence, 25, 377-386. doi: 10.1111/jora.12135. [PubMed: 26052189]

Ram N \& Diehl M (2015). Multiple-time-scale design and analysis: Pushing toward real-time modeling of complex developmental processes In Diehl M, Hooker K, \& Sliwinski MJ (Eds.), Handbook of intraindividual variability across the lifespan (pp. 308-323). New York, NY, US: Routledge/Taylor \& Francis Group.

Raudenbush SW, \& Bryk AS (2002). Hierarchical linear models: Applications and data analysis methods (2nd ed.). Thousand Oaks, CA, US: Sage Publications, Inc.

Rothbart ML (2012). Becoming who we are. New York, New York: Guilford Press.

Rothenberg WA, Hussong AM, Langley HA, Egerton GA, Halberstadt AG, Coffman JL, Mokrova I, \& Costanzo PR (2017). Grateful parents raising grateful children: Niche selection and socialization of child gratitude. Applied Developmental Science, 21, 106-120. DOI: 10.1080/10888691.2016.1175945. [PubMed: 28943753]

Saucier G (1994). Mini-Markers: A brief version of Goldberg's unipolar Big-Five markers. Journal of Personality Assessment, 63, 506-516. doi:10.1207/s15327752jpa6303_8 [PubMed: 7844738]

Scheier MF, Carver CS, \& Bridges MW (1994). Distinguishing optimism from neuroticism (and trait anxiety, self-mastery, and self-esteem): A reevaluation of the Life Orientation Test. Journal of Personality and Social Psychology, 67, 1063-1078. doi:10.1037/0022-3514.67.6.1063 [PubMed: 7815302]

Scherbaum CA, \& Ferreter JM (2009). Estimating statistical power and required sample sizes for organizational research using multilevel modeling. Organizational Research Methods, 12, 347367. doi: $10.1177 / 1094428107308906$

Shiffman S, Stone AA, \& Hufford MR (2008). Ecological momentary analysis. Annual review of Clinical Psychology, 4, 1-393.

Snijders TA (2005). Power and sample size in multilevel linear models. Encyclopedia of statistics in behavioral science.

Snyder J (2002). Reinforcement and coercion mechanisms in the development of antisocial behavior: Peer relationships In Reid JB, Patterson GR, \& Snyder J (Eds.), Antisocial behavior in children and adolescents: A developmental analysis and model for intervention (pp. 101-122). Washington DC, US: APA.

Stöber J (2001). The Social Desirability Scale-17 (SDS-17): Convergent validity, discriminant validity, and relationship with age. European Journal of Psychological Assessment, 17, 222-232. doi: 10.1027//1015-5759.17.3.222

Super CM, \& Harkness S (1986). The developmental niche: A conceptualization at the interface of child and culture. International Journal of Behavioral Development, 9, 545-569.

Tudge JRH, Freitas LBL, \& O'Brien LT (2015). The virtue of gratitude: A developmental and cultural approach. Human Development, 58, 281-300.

Wagner NJ, Mills-Koonce WR, Willoughby MT, Zvara B, Cox MJ, \& The Family Life Project Key Investigators (2015). Parenting and children's representations of family predict disruptive and callous-unemotional behaviors. Developmental Psychology, 51, 935-948. doi:10.1037/a0039353 [PubMed: 26010385] 
Watson D, Clark LA, \& Tellegen A (1988). Development and validation of brief measures of positive and negative affect: The PANAS scales. Journal of Personality and Social Psychology, 54, 10631070. doi:10.1037/0022-3514.54.6.1063 [PubMed: 3397865]

Wood AM, Froh JJ, \& Geraghty AA (2010). Gratitude and well-being: A review and theoretical integration. Clinical Psychology Review, 30, 890-905. doi:10.1016/j.cpr.2010.03.00 [PubMed: 20451313] 


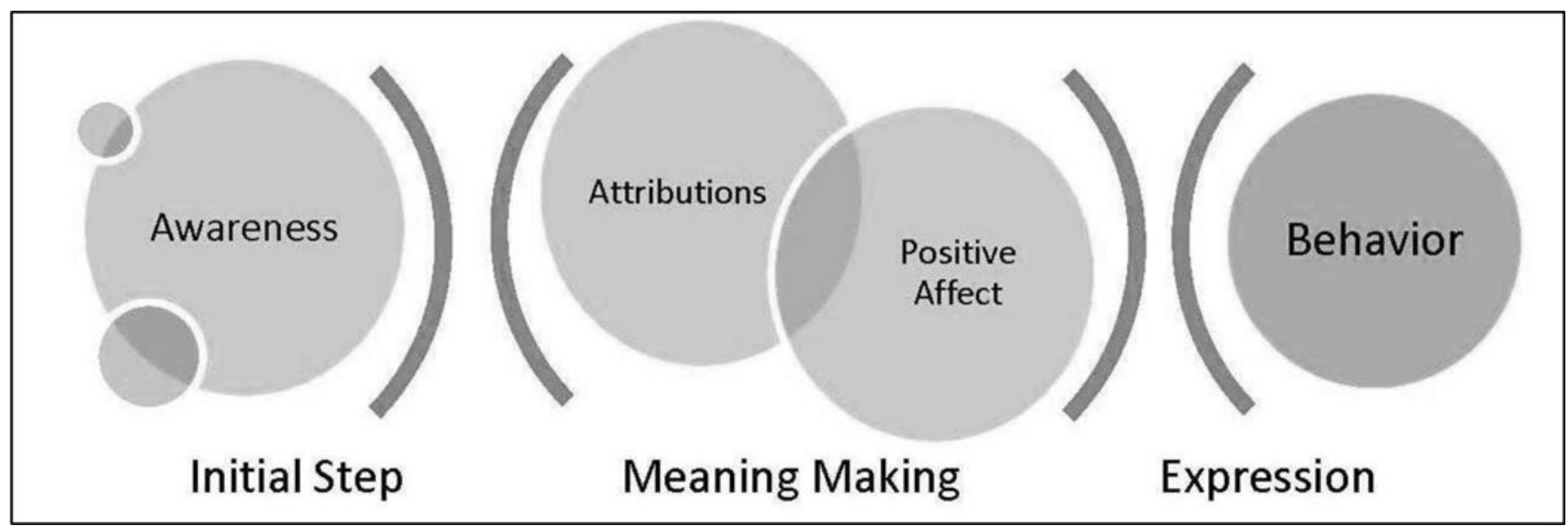

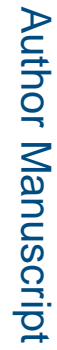

Figure 1.

A Process Model of Children's Gratitude 
Table 1.

Psychometric Properties of Analysis Variables

\begin{tabular}{|l|l|c|c|c|c|c|c|}
\hline & & $\mathbf{1}$ & $\mathbf{2}$ & $\mathbf{3}$ & $\mathbf{4}$ & $\mathbf{5}$ & $\mathbf{6}$ \\
\hline & BETWEEN-DYAD VARIABLES & & & & & & \\
\hline 1 & Parent Sensitivity & -- & & & & & \\
\hline 2 & Parent Gratitude & $.21^{*}$ & -- & & & & \\
\hline 3 & ${ }^{a}$ Parent-Reported Child Socioemotional Functioning & $.36^{* * *}$ & $.32^{*}$ & -- & & & \\
\hline 4 & ${ }^{2}$ Child-Reported Child Socioemotional Functioning & .07 & $.27^{* *}$ & .13 & & & \\
\hline & WITHIN-DYAD VARIABLES & & & & & & \\
\hline 5 & Parent Socialization Acts & $.19^{+}$ & $.23^{*}$ & .08 & $.29^{*}$ & & \\
\hline 6 & Child Gratitude Displays & $.19^{+}$ & $.29^{* *}$ & $.32^{* *}$ & $.18^{+}$ & $.73^{* * *}$ & \\
\hline $\begin{array}{l}\text { Mean } \\
\text { Range } \\
\text { Standard Deviation }\end{array}$ & $\begin{array}{c}4.64 \\
1.04\end{array}$ & $\begin{array}{c}6.0 .12 \\
1.31\end{array}$ & $\begin{array}{c}-2.05-1.51 \\
0.83\end{array}$ & $\begin{array}{c}-3.31-1.58 \\
0.83\end{array}$ & $\begin{array}{c}1.11 \\
0-2.33 \\
0.39\end{array}$ & $\begin{array}{c}0.05-2.00 \\
0.38\end{array}$ \\
\hline
\end{tabular}

Note:

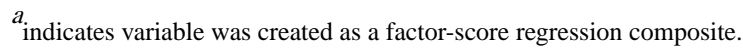

${ }_{p<.10}^{+}$

$p^{*}<.05$

*** $p<.01$

**** $p<.001$ 
Table 2.

Results of Multilevel Models Testing Predictors of Parents' Daily Reports of Children's Gratitude

\begin{tabular}{|l|l|l|l|l|l|l|}
\hline & \multicolumn{2}{|l|}{ Model for Hypothesis 1 \& 2 } & \multicolumn{2}{|l|}{ Model for Hypothesis 2 } & \multicolumn{2}{|c|}{ Model for Hypothesis 3 } \\
\hline & \multicolumn{1}{|c|}{$\mathbf{t}$} & \multicolumn{1}{|c|}{$\mathbf{t}$} & \multicolumn{1}{|c|}{ b } & \multicolumn{1}{|c|}{ t } \\
\hline Within-Dyad Daily Time Spent with Child & 0.03 & $3.97^{* * *}$ & 0.03 & $4.01^{* * * *}$ & 0.03 & $3.97^{* * * *}$ \\
\hline Between-Dyad Daily Time Spent with Child & 0.04 & $1.79^{+}$ & 0.04 & 1.62 & 0.04 & 1.64 \\
\hline Within-Dyad Parent Daily Socialization Acts & 0.62 & $19.51^{* * *}$ & 0.62 & $19.33^{* * *}$ & 0.62 & $19.52^{* * *}$ \\
\hline Between-Dyad Parent Daily Socialization Acts & 0.87 & $14.77^{* * *}$ & 0.87 & $14.05^{* * *}$ & 0.85 & $14.25^{* * *}$ \\
\hline Sensitive Parenting & & & -0.01 & -0.22 & & \\
\hline Parent Gratitude & & & 0.03 & $1.75^{+}$ & & \\
\hline $\begin{array}{l}\text { Parent-report of Children's Socio-Emotional } \\
\text { Functioning }\end{array}$ & & & & & .07 & $3.07^{* * *}$ \\
\hline $\begin{array}{l}\text { Child-report of Children's Socio-Emotional } \\
\text { Functioning }\end{array}$ & & & & & -.02 & -0.80 \\
\hline Proportion of Variance Accounted for by Model & & .5274 & & .5266 & & .5276 \\
\hline
\end{tabular}

Note:

${ }^{+}{ }_{\text {indicates }}<.10$,

is $p<.05$,

** is $p<.01$

**** is $p<.001$

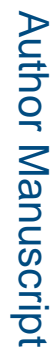

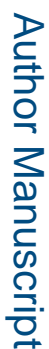

